\title{
Kirschner Wires Caused Unexpected Complications of Femoral Neck Fracture
}

\author{
F.G.M. Khallaf M.T. Al-Akkd I.M. Al-Kussary A. Al-Mi Kami \\ Department of Orthopedics, Al-J ahra Hospital, Ministry of Health, Kuwait
}

\section{Key Words}

Femoral neck fracture $\cdot$ Kirschner wires $\cdot$ Internal fixation - Metal migration $\cdot$ Rectal bleeding

\begin{abstract}
Objective: To report a unique complication of the surgical treatment of femoral neck fractures. Clinical Presentation and Intervention: A young adult presented with lower abdominal pain and bleeding per rectum caused by rectal transfixion by Kirschner wires ( $\mathrm{K}$ wires). The wires were used to fix a fracture on the neck of the femur during the Iraqi occupation of Kuwait. A plain X-ray showed an old united fracture of the neck of the left femur with coxa magna, mild coxa vara and mild secondary osteoarthritis of the left hip joint. Limited barium enema disclosed transfixion of the rectum by two radiopaque $\mathrm{K}$ wires in the pelvis with rectal track formation around them. The complication necessitated a laparotomy and a major dissection to remove the $\mathrm{K}$ wires. Conclusion: The $\mathrm{K}$ wire provided an immediate solution during a difficult period. However, since it is not normally used for this purpose, it caused subsequent complications that were resolved by laparotomy and a major dissection.
\end{abstract}

Copyright $(2002$ S. Karger AG, Basel

\section{Introduction}

While there is little debate that young patients with femoral neck fractures should have their fractures reduced and internally fixed [1], controversy still exists regarding the device to be used for internal fixation [2]. Numerous implants are available for fixation of femoral neck fractures including threaded Knowles pins, Asnis screws, Deyerle pins, Garden screws, Hansson hook pins, cannulated screws and compression hip screw [2-5]. However, Kirschner wires (K wires) are not used for this purpose. Two frequent complications of femoral neck fractures are nonunion and avascular necrosis of the femoral head [5]. We are reporting a peculiar complication of an exceptionally odd method of fixation of femoral neck fracture using $\mathrm{K}$ wires in Kuwait during the Gulf war.

\section{Case Report}

A 36-year-old Egyptian male, a manual worker, was admitted to Al-Razi, Orthopedic Hospital, Kuwait on December 24, 1990 after being beaten by Iraqi soldiers and forced to jump from the first floor of a building. Clinical and radiological examination revealed Garden IV fracture of the neck of the left femur. The next day the patient was operated on by closed reduction on an orthopedic table, and internal fixation was carried out using multiple $\mathrm{K}$ wires because the routinely used implants in femoral neck fracture fixation were not available. The patient was allowed protected and partial weight-bearing walking exercises on discharge from the hospital. The circumstances prevented the follow-up of the patient, who found himself capable of unaided walking with a mild limp 4 months later.

\begin{tabular}{ll}
\hline KARGER & ( ) 2002 S. Karger AG, Basel \\
Fax +4161306 1234 & 1011-7571/02/0113-0164\$18.50/0 \\
$\begin{array}{l}\text { E-Mail karger@karger.ch } \\
\text { www.karger.com }\end{array}$ & $\begin{array}{l}\text { Accessible online at: } \\
\text { www.karger.com/journals/mpp }\end{array}$
\end{tabular}

Dr. F.G.M. Khallaf

Orthopedic Department

Al-Jahra Hospital, PO Box 21416

13075 Safat (Kuwait)

Tel./Fax +9654899617 
Fig. 1. Anteroposterior $\mathrm{X}$-ray view of the pelvis with both hips showing an old united fracture of the neck of the left femur with three $\mathrm{K}$ wires migrating into the pelvis.

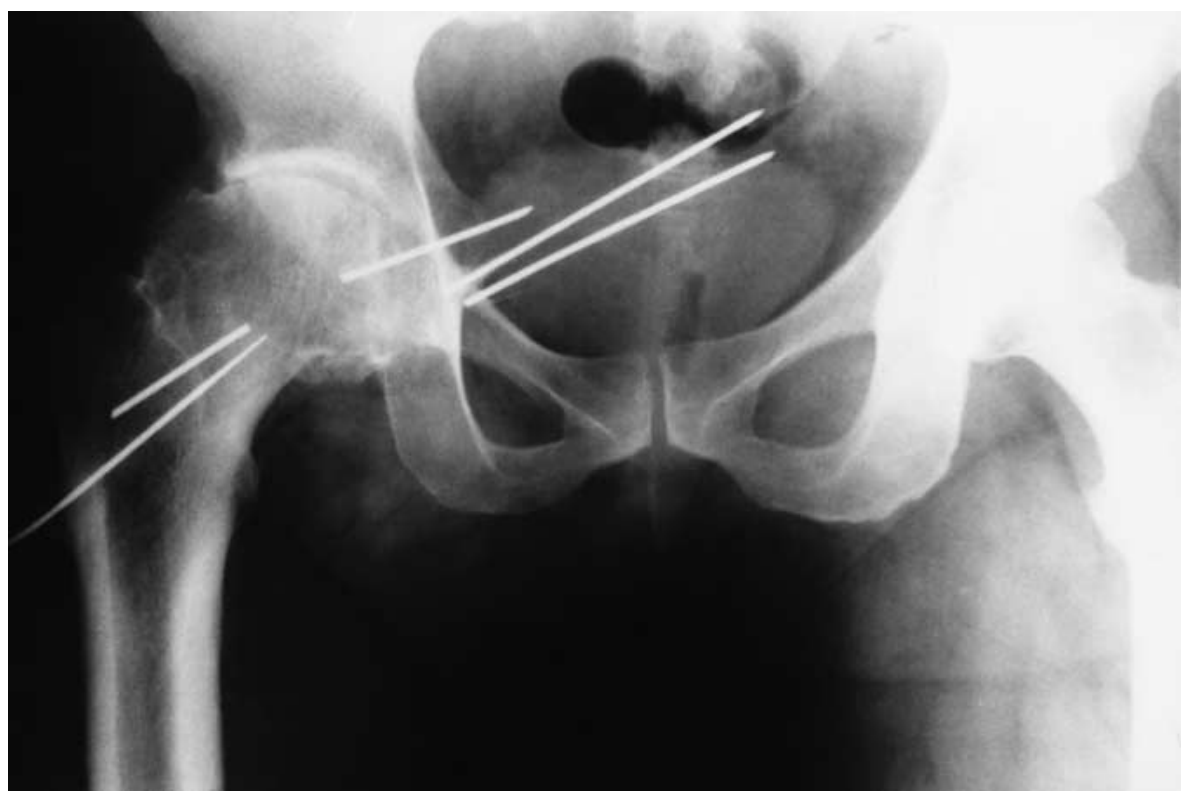

In the middle of March 1994 the patient started to experience pain in the left groin and left lower abdomen together with episodes of scanty fresh bleeding per rectum. On examination, there was a mild tenderness over the left iliac fossa and left inguinal region.

On PR examination, two K wires were felt transfixing the rectum about $5 \mathrm{~cm}$ from the anal region. A plain X-ray (fig. 1) showed an old united fracture of the neck of the left femur with coxa magna, mild coxa vara and mild secondary osteoarthritis of the left hip joint. Two of the $\mathrm{K}$ wires had migrated completely intrapelvic. A third $\mathrm{K}$ wire was broken in the femoral neck and its proximal part had penetrated the left hip joint extending partially into the pelvis. The fourth $\mathrm{K}$ wire had backed out and protruded into the left thigh muscles. Limited barium enema (fig. $2 \mathrm{a}, \mathrm{b}$ ) disclosed transfixion of the rectum by two radiopaque $\mathrm{K}$ wires in the pelvis with small rectal track formation around them. In April 6, 1994 a laparotomy was performed. After difficult dissection, the two transfixing $\mathrm{K}$ wires were removed. The patient was discharged 8 days later after a mild postoperative bleeding per rectum had been stopped.

\section{Discussion}

In young adult patients, intracapsular fractures of the proximal part of the femur are uncommon and mostly the result of high velocity trauma. Nonunion and avascular necrosis with late segmental collapse of the femoral head are the two principal complications of these fractures.

In 1976, Protzman and Burkhalter [6] reported disastrous results including very high rates of osteonecrosis and nonunion necrosis ( 86 and 59\%, respectively) in 22 patients who had femoral neck fractures and were less than 55 years old.

Kirschner Wires Caused Unexpected

Complications of Femoral Neck Fracture
However, in 1994 Kyle [7] reported lower rates of osteonecrosis (20-30\%) and nonunion necrosis (1520\%). Bray et al. [8] mentioned the overall complications of pinning the femoral neck fractures using Knowles pins. Besides the aforementioned main complications, there were also loss of reduction, varus collapse and pins cutting through the femoral head and pin irritation to the hip joint and thigh muscles [8].

To our knowledge, there has been no report of fixation of femoral neck fractures in active young patients using smooth $\mathrm{K}$ wires as it was done on our patient. Amazingly, the fracture united with mild coxa vara and without avascular necrosis. However, disastrous complications of hip joint penetration and intrapelvic migration of the $\mathrm{K}$ wires with rectum transfixion necessitated laparotomy and difficult dissection to remove the wires. In 1978 Baker and Barrick [9] reported a significant incidence of complications attributable to the use of small-diameter Deyerle multiple pins, namely breakage of the fixation pins and penetration of the pins through the femoral head into the hip joint, but not intrapelvic. The surgeon may significantly reduce the incidence of complications of internal fixation of femoral neck fractures by achieving an adequate reduction and selecting a fixation device that firmly anchors to the bone of the femoral head, rigidly controls and stabilizes the fracture site. 

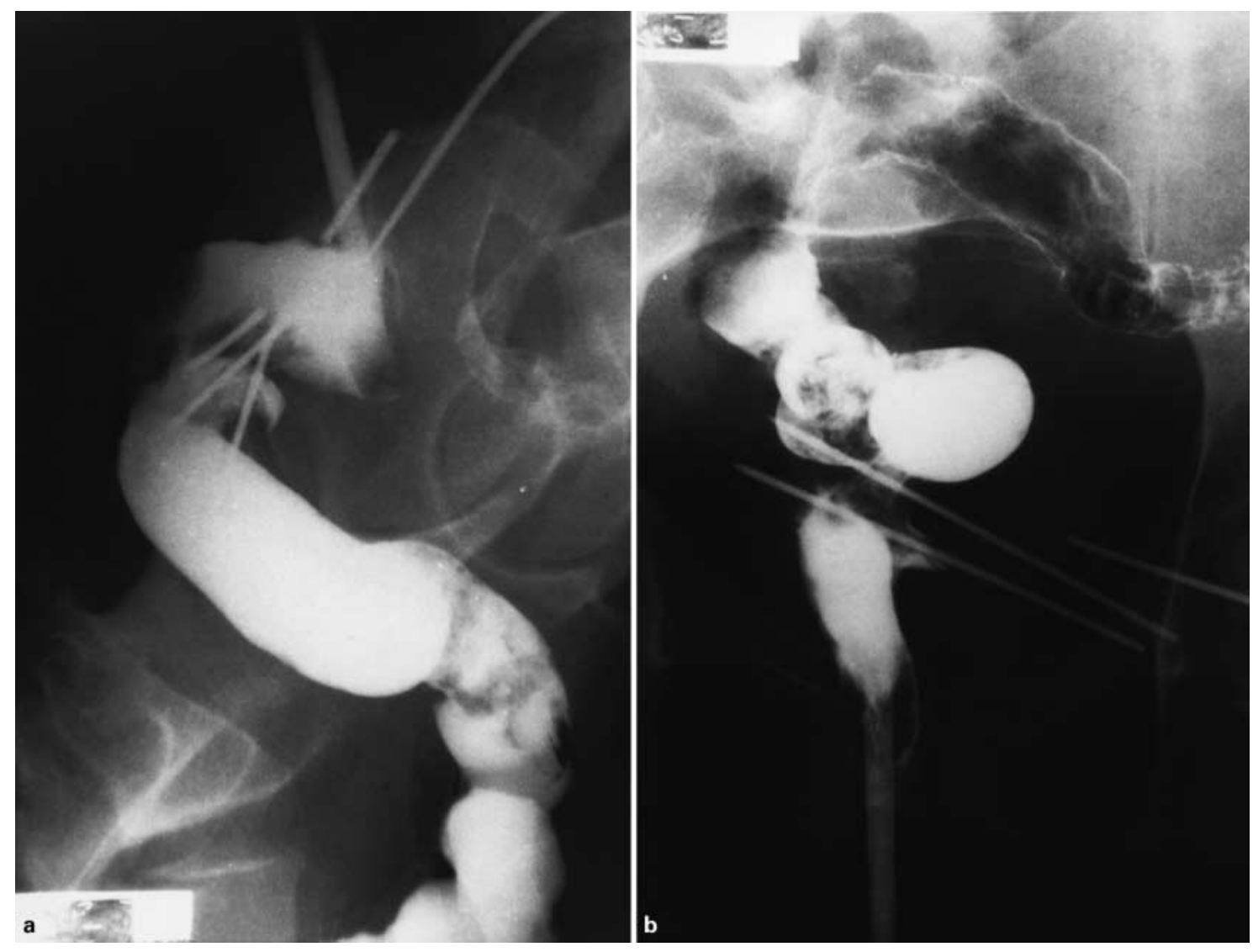

Fig. 2. Barium enema of the anteroposterior and lateral views showing transfixion of the rectum by two $K$ wires in the pelvis with a small rectal track around them.

\section{Conclusion}

The $\mathrm{K}$ wire provided an immediate solution during a difficult period. However, it caused subsequent complication of a loose and improper fixation of a femoral neck fracture that was resolved by laparotomy and a major dissection.

\section{Acknowledgment}

The authors would like to thank Mrs. Ayat El-Naggar for assisting with the preparation of the manuscript.

\section{References}

1 Swiontkowski MF, Winquist RA, Hansen ST: Fractures of the femoral neck in patients between the age of 12 and 49 years. J Bone Joint Surg Am 1984;66:837-846.

2 Arnold WD, Lyden JP, Minkoff J: Treatment of intra-capsular fractures of the femoral neck with special reference to percutaneous Knowles pinning. J Bone Joint Surg 1974;56:254-260.

3 Frandsen PA: Osteosynthesis of displaced fractures of the femoral neck. Acta Orthop Scand 1979;50:443-451.
4 Sormgvist B, Hansson LI, Nilsson LT, Thorngren KG: Hook-pin fixation in femoral neck fractures. Clin Orthop 1987;218:58-70.

5 Garden RS: Reduction and fixation of subcapital fractures of the femur. Orthop Clin North Am 1974;5:683-696.

6 Protzman PR, Burkhalter WE: Femoral neck fractures in young adults. J Bone Joint Surg 1976;58:689-693.
7 Kyle RF: Fractures of the proximal part of the femur. J Bone Joint Surg 1994;76:924-941.

8 Bray TJ, Smith-Hoefer E, Hooper A, Trimmerman L: The displaced femoral neck fracture: Internal fixation versus bipolar endoprosthesis: Results of a prospective randomized comparison. Clin Orthop 1988;230:127-142.

9 Baker GI, Barrick EF: Deyerle treatment for femoral neck fractures. J Bone Joint Surg Am 1978;60:269-282. 